\title{
Ambiances
}

anbiances Environnement sensible, architecture et espace urbain Éditos | 2013

\section{Ouverture au monde sensible}

\author{
Jean-Paul Thibaud
}

\section{OpenEdition \\ Journals}

Édition électronique

URL : http://journals.openedition.org/ambiances/176

DOI : 10.4000/ambiances. 176

ISSN : 2266-839X

\section{Éditeur :}

Direction Générale des Patrimoines - DAPA - MCC, UMR 1563 - Ambiances Architectures Urbanités (AAU)

\section{Référence électronique}

Jean-Paul Thibaud, «Ouverture au monde sensible », Ambiances [En ligne], Éditos, mis en ligne le 11 février 2013, consulté le 22 septembre 2020. URL : http://journals.openedition.org/ambiances/176 ; DOI : https://doi.org/10.4000/ambiances. 176

Ce document a été généré automatiquement le 22 septembre 2020.

\section{(c) (i) () $\Theta$}

Ambiances is licensed under a Creative Commons Attribution-NonCommercial-NoDerivatives 4.0 International License. 


\title{
Ouverture au monde sensible
}

\author{
Jean-Paul Thibaud
}

1 L'ouverture de la Revue Ambiances marque une étape importante dans la reconnaissance du monde sensible comme domaine de recherche pluridisciplinaire, comme enjeu actuel de conception architecturale et urbaine, et comme terrain d'expérimentation et de création artistique. L'objectif est de taille et les travaux ne manquent pas qui s'intéressent à l'environnement sensoriel des espaces habités.

2 Ce numéro d'ouverture en témoigne tant sont divers et variés les cadres de pensée mobilisés, les perspectives possibles en la matière, les objets d'étude mis en chantier. Ainsi peut-on y lire la proposition d'une esthétique des atmosphères, l'ethnographie sensible d'un espace public parisien, une caractérisation de l'espace urbain à l'aune des mobilités pédestres, la lecture attentive d'une mise en récit des ambiances insulaires, la description phénoménale d'une gated community cairote... De plus, le compte-rendu de deux ouvrages traitant de la ville sensible amorce une autre rubrique de la revue.

3 Autant d'explorations qui inaugurent le propos de la revue et indiquent des pistes de recherche en cours. Ces premiers articles disent également combien les changements en profondeur des territoires et des milieux de vie contemporains appellent de nouvelles démarches et suscitent de nouveaux modèles d'intelligibilité pour en rendre compte. Encore ne s'agit-il là que d'une première esquisse. D'autres types d'apport et modes d'approche viendront progressivement compléter le tableau et étayer le pluralisme revendiqué de la revue Ambiances.

4 Par ailleurs, notons le caractère bilingue affirmé de la revue. C'est que celle-ci vise à développer plus avant des rencontres et des perméabilités entre le monde de la recherche francophone et anglophone. Le langage ne saurait être trop sous-estimé dans un domaine aussi sensible que le nôtre! A l'heure de l'hybridation et de la traduction, il devient plus que jamais indispensable de se préserver d'un certain «nationalisme méthodologique » ou de toute autre forme d'unidimensionnalité linguistique.

5 Prendre acte de l'intérêt grandissant porté au monde des sens conduit enfin à donner toute sa place aux divers supports, archives et matériaux sensibles issus des travaux de recherche. C'est ainsi que la revue Ambiances exprime dès à présent la volonté d'accueillir en son sein tous types de documents sonores, photographiques, 
vidéographiques, audiovisuels, etc., susceptibles de servir un questionnement ou nourrir une investigation.

6 Jean-Paul Thibaud

Pour le comité de rédaction 